\title{
28 Research Suare \\ Etiological Detection for Cerebral Parenchymal Opportunistic Infections in AIDS Patients by PCR
}

Bo Liang

Siyuan Yang

Tingyu Liang

Hongxin Zhao

Xinghuan Ding

Fang Wang

Enshan Feng ( $\sim$ enshanfeg@126.com )

\section{Research}

Keywords: AIDS, cerebral parenchymal lesion, opportunistic infections, PCR, FFPET

Posted Date: June 1st, 2020

DOI: https://doi.org/10.21203/rs.3.rs-31872/v1

License: (c) (i) This work is licensed under a Creative Commons Attribution 4.0 International License. Read Full License 


\section{Abstract}

Background: Central nervous system (CNS) opportunistic infections (OIs) is one of the most important complication in Acquired Immune Deficiency Syndrome (AIDS) patients. As far as the cerebral parenchymal Ols (encephalitis) are concerned, the sensitivity and specificity of pathogens routine test methods are not highly acceptable at present.

Objective: Detect the pathogens of cerebral parenchymal Ols in AIDS patients by polymerase chain reaction (PCR), to evaluate the utility of this method, and observe the etiology characteristics of cerebral parenchymal Ols and their impact on the prognosis in AIDS patients.

Methods: We conducted a retrospective study design involving 33 formalin-fixed paraffin-embedded tissue (FFPET) samples of cerebral inflammatory lesions in AIDS patients from 2012 to 2020 were retrieved from the Department of Pathology, Beijing Ditan hospital affiliated to Capital Medical University. Pathogen-specific primers were used to detect DNA from cytomegalovirus (CMV), toxoplasma gondii (TG) and John Cunningham virus (JCV), via real-time PCR. Follow-up visits were conducted by telephone and outpatient service. Survival time after operation was counted.

Results: Of 33 samples sent for PCR, 90.91\% (30/33) were positive, 33 pathogens detected. JCV accounted for $60.61 \%$ (20/33) of all causes of cerebral parenchymal Ols, 21.21\% (7/33) for CMV, 18.18\% (6/33) for TG. IgG antibody against TG in serum $(P=0.005)$ and in CSF $(P=0.013)$ obviously correlated with TG expression in FFPET. The 0 pathogen patients tend to suffer from solitary lesion $(P=0.018)$. JCV positive patients in FFPET tended to have higher odds of death $(P=0.0096)$, whereas patients with TG positive showed lower odds of death $(P=0.0431)$.

Conclusion: JCV is the most prevalent pathogen of cerebral parenchymal Ols among AIDS patients, and tend to have a poor prognosis. The utility of the diagnostic method for pathogen identification by PCR combined with the investigation of etiological characteristics may improve the diagnosis and prognosis of AIDS related cerebral parenchymal Ols patients.

\section{Introduction}

Central nervous system ( $C N S)$ opportunistic infections (OIs) is a major cause of morbidity and mortality among Acquired Immune Deficiency Syndrome (AIDS) patients, it mainly includes meningitis, encephalitis and meningoencephalitis. The pathogen involves viruses, bacteria, mycobacterium, fungus, parasites and other pathogenic microorganisms ${ }^{[1,2]}$.

Unfortunately, for the encephalitis, which is cerebral parenchymal infections, the available and frequently used means of diagnosis are generally limited, a substantial part of the microbiological diagnoses, such as cytomegalovirus (CMV), toxoplasma gondii (TG) and John Cunningham virus (JCV), are difficult to ascertain by routine diagnostic methods, that patients can only be treated empirically. As a result, choose appropriate clinical specimens and laboratory test method is very important for the diagnosis of pathogenic microorganisms in CNS Ols. In recent years, real-time polymerase chain reaction $(R T-P C R)$ has been proved that had advantages of high sensitivity and specificity, as well as fast operation and low risk of laboratory pollution in the process of CNS Ols diagnosis ${ }^{[3]}$.

In recent years, there are many articles at home and abroad ${ }^{[4-7]}$ demonstrated the superiority of CSF-PCR in CNS Ols diagnosis. These reports all suggested that cryptococcal meningitis accounted for great majority of CNS OIs, cryptococcus is the most common pathogen, the incidence of other pathogens is only $40 \%$ or less ${ }^{[4-6]}$. While, to some extent, CSF-PCR is probably only sensitive to the diagnosis of meningitis, but not to encephalitis, thus leading to lots of diagnoses missed. The formalin-fixed paraffin-embedded tissue (FFPET) PCR was proved efficient in detecting pathogens abroad ${ }^{[8]}$, which is not currently used for routine test mean in China, especially in AIDS patients. Based on this consideration, in this study, we establish a set of FFPET PCR assay system, targets CMV, TG and JCV. The FFPET

Page $2 / 16$ 
samples from infected cerebral parenchymal specimens were sectioned for DNA lysate preparation, which then subjected to PCR analysis to determine the presence of CMV, TG and JCV. This study aimed to evaluate the utility of using PCR assay in determining the etiologies, and demonstrate characteristics of encephalitis infected by various pathogens in AIDS patients along with the impact on prognosis.

\section{Materials And Methods Patients population}

We conducted a retrospective study of 33 AIDS patients whose FFPET samples with histopathologically diagnosed inflammatory lesions, at the Department of Pathology of Beijing Ditan Hospital, which is an infectious disease hospital, affiliated to Capital Medical University from 1 May 2013 to 29 February 2020, in Beijing, China.

Demographic information, such as age, gender, and clinical features (include symptoms, imaging manifestations, surgical procedure, characteristics of surgical specimens, $\mathrm{CD}_{4}{ }^{+} \mathrm{T}$ lymphocyte count, serum/CSF HIV RNA viral load, pathogen test from blood/CSF, CT/MRI characteristics, complications, postoperative overall survival time, and so on) were collected on a standardized case report form $(C R F)$ by the trained physician. Trained radiologists and pathologist were also invited to assist in making the diagnosis. The study was approved by Beijing Ditan hospital of Capital Medical University Ethics Committee.

Pathogen test information from blood/CSF include: CSF routine and biochemical tests, Gram stain, India ink stain, Cryptococcal antigen ( $\mathrm{Cr} A g$ ) detection, Immunoglobulin $(\mathrm{Ig}) \mathrm{G}$ or M antibodies against CMV/TG, bacterial/fungal cultures, Acid fast bacilli stain.

Patients were eligible for the study if they had: (1) confirmed with HIV infection; (2) cerebral parenchymal lesions which were identified by imaging examination; (3) received surgical operation; (4) the FFPET from cerebral parenchymal specimens; (5) histopathological diagnosis only indicated inflammatory lesions (Fig. 1); (6) relative detailed and perfect clinical data; and (7) pathogens of cerebral parenchymal lesions are still unclear based on imaging, laboratory and pathological findings. Exclusion criteria for enrollment included: (1) it's uncertain that there is cerebral parenchymal lesions by imaging examination; (2) the diagnosis was definite by imaging, laboratory and pathological findings; (3) patients had not received surgical operation; (4) no FFPET from cerebral parenchymal specimens; or (5) interruption of follow-up.

\section{FFPET testing}

\section{Tissue Sectioning for Histological Analysis.}

After trimming of the 33 FFPET samples of blocks obtained, $5 \mu \mathrm{m}$ sections of the tissue were taken using a microtome. The sections were then stained with haematoxylin and eosin (H\&E), using an automated H\&E staining system (Leica Auto Stainer $\mathrm{XL}$ ). The H\&E stained slides were reviewed under the light microscope at the Department of Pathology, SBAHS, to confirm the previous diagnosis. The H\&E stained tissue slides were also used primarily as microscopic controls to ensure that the tissue sections used in the PCR were inflammatory/infective/demyelinating tissue.

\section{DNA Extraction.}

Ten micrometre $(10 \mu \mathrm{m})$ sections of the tissue were taken using a microtome. To avoid carry-over of the samples and contamination, the microtome blade was changed after each section and all surfaces were also cleaned with xylene after each tissue section. The $10 \mu \mathrm{m}$ sections were placed into a sterile DNase-free tube for nucleic acid extraction with 
GeneRead DNA FFPE kit (QIAGEN, Cat NO. 180134). Following method described previously, DNA extraction protocol involved deparaffinization using Deparaffinization Solution and tissue lyse with an incubation with $55 \mu$ RNase-free water, $25 \mu \mathrm{l}$ Buffer $\mathrm{FTB}$, and $20 \mu \mathrm{l}$ proteinase $\mathrm{K}$ at $56^{\circ} \mathrm{C}$ for $1 \mathrm{~h}$,RNA removal using incubation with $25 \mu \mathrm{l}$ Rase $\mathrm{A}$ and incubate for $2 \mathrm{~min}$ at room temperature. Finally, the elution buffer was Buffer ATE and $30 \mu \mathrm{l}$ was used for DNA elution. Total extracted DNA samples were stored at $-80^{\circ} \mathrm{C}$ for pathogen's testing.

\section{RT-PCR Tests}

Real-Time PCR detection kits for CMV, JCV and TG (Cat NO. Z-OD-0022-01, OD-0230-01, ZD-0075-01 respectively) were purchased from Liferiver Biological Technology Co. Ltd (Shanghai, China). The TaqMan probe provided in the kit could be used for the amplification and detection for CMV, JCV and TG in which plasmid DNA and RNAase-free water served as the positive and negative controls, respectively. The $40.0 \mu \mathrm{l} \mathrm{PCR}$ mix system consisted of $36.0 \mu \mathrm{l}$ of RT-PCR reaction mix, $4.0 \mu \mathrm{l}$ of extracted DNA template, and $0.4 \mu \mathrm{l}$ of enzyme mixed according to the manufacturer's description. RT-PCR amplifications using SLAN-96P Thermal Cycler (Hongshi, Shanghai, China), the RT-PCR according to the following reaction conditions: $37^{\circ} \mathrm{C}$ for $2 \mathrm{~min} ; 94^{\circ} \mathrm{C}$ for $2 \mathrm{~min} ; 40$ amplification cycles of $93^{\circ} \mathrm{C}$ for $15 \mathrm{~s}, 60^{\circ} \mathrm{C}$ for $60 \mathrm{~s}$. Each sample was determined for three replicates. The criterion of positive result is that cycle threshold (Ct) value is $\leq 38$ cycles.

\section{Statistical analysis}

Correlation analysis between pathogen detection and clinical characteristics were analyzed by Chi-square test. Survival time after operation was calculated by the Kaplan-Meier method. $\mathrm{P}<0.05$ was considered statistically significant. All statistical analyses were evaluated using SPSS 22.0.

\section{Results}

The demographic characteristics of the 33 cases showed mean age of patients to be $38.15 \pm 10.02$ years (median age, 36 years; range 23-61 years), comprising 31 males and 2 females given a $15.5: 1$ male to female ratio.

\section{Pathogen(s) detecting in FFPET}

Pathogens were detected in 30 (90.91\%) FFPET samples, the total quantity of pathogen was 33 . The number of patients diagnosed with one or more pathogens is shown in Table 1. JCV was the most common pathogen found (20/33, $60.61 \%)$. There were almost equal numbers of detection of $\operatorname{CMV}(7 / 33,21.21 \%)$ and TG $(6 / 33,18.18 \%)$. There were CMV/JCV $(1 / 33,3.03 \%)$ as well as TG/CMV $(2 / 33,6.06 \%)$ coinfection detected in this patient population. No case of $\mathrm{CMV} / \mathrm{JCV} / \mathrm{TG}$ was detected by PCR. 
Table 1

Characteristics of patients with FFPET pathogen(s)

\begin{tabular}{|c|c|c|c|c|c|c|c|}
\hline Pathogens & $\begin{array}{l}\text { Individual } \\
\text { cerebral } \\
\text { parenchyma } \\
\text { prevalence }\end{array}$ & 1 pathogen & $\begin{array}{l}\text { No. of } \\
\text { cases }\end{array}$ & 2 pathogens & $\begin{array}{l}\text { No. of } \\
\text { cases }\end{array}$ & 0 pathogen & $\begin{array}{l}\text { No. of } \\
\text { cases }\end{array}$ \\
\hline CMV & $7(21.21 \%)$ & CMV & $4(12.12 \%)$ & CMV/JCV & $1(3.03 \%)$ & & $3(9.09 \%)$ \\
\hline JCV & $20(60.61 \%)$ & JCV & $19(57.58 \%)$ & $\mathrm{JCV} / \mathrm{TG}$ & $0(0 \%)$ & & \\
\hline TG & 6(18.18\%) & TG & $4(12.12 \%)$ & TG/CMV & $2(6.06 \%)$ & & \\
\hline Total & $\begin{array}{l}33 \\
\text { pathogens }\end{array}$ & $27 / 33(81.82 \%)$ & & $3 / 33(9.09 \%)$ & & $3 / 33(9.09 \%)$ & \\
\hline
\end{tabular}

\section{Correlation analysis between pathogens and clinical characteristics in patients.}

The 33 cases were totally tested for $\mathrm{CD}_{4}{ }^{+} \mathrm{T}$ lymphocyte (mean value 92, range 5-610) and HIV RNA viral load in serum (mean value 6215, range 0-3478226), but there was no significant difference between each pathogen (Table 2). 
Table 2

Correlation analysis between pathogens and clinical characteristics in patients.

\begin{tabular}{|c|c|c|c|c|c|}
\hline \multirow[t]{2}{*}{ Feature } & $\begin{array}{l}\text { CMV } \\
\text { (FFPET) }\end{array}$ & $\begin{array}{l}\text { JCV } \\
\text { (FFPET) }\end{array}$ & $\begin{array}{l}\text { TG } \\
\text { (FFPET) }\end{array}$ & $\begin{array}{l}\text { No pathogen } \\
\text { (FFPET) }\end{array}$ & $\begin{array}{l}P \\
\text { value }\end{array}$ \\
\hline & No. (\%) & No. (\%) & No. (\%) & No. (\%) & \\
\hline Age (years) & & & & & 0.525 \\
\hline$\leq 36$ & $2(28.6)$ & $10(50.0)$ & $4(66.7)$ & $1(33.3)$ & \\
\hline$₫ 36$ & $5(71.4)$ & 10(50.0) & $2(33.3)$ & $2(66.7)$ & \\
\hline Gender & & & & & 0.668 \\
\hline Male & $6(85.7)$ & $19(95.0)$ & $5(83.3)$ & $3(100.0)$ & \\
\hline Female & $1(14.3)$ & $1(5.0)$ & $1(16.7)$ & $0(0.0)$ & \\
\hline${ }_{*}^{\mathrm{CD}_{4}}{ }^{+} \mathrm{T}$ lymphocyte count(cells/ul) & & & & & 0.167 \\
\hline$\leq 92$ & $4(57.1)$ & $11(55.0)$ & $4(66.7)$ & $0(0.0)$ & \\
\hline$>92$ & $3(42.9)$ & $9(45.0)$ & $2(33.3)$ & $3(100.0)$ & \\
\hline $\begin{array}{l}\text { HIV RNA viral load } \\
\text { (serum)* }\end{array}$ & & & & & 0.001 \\
\hline$\leq 6215$ & $0(0.0)$ & $14(70.0)$ & $1(16.7)$ & $2(66.7)$ & \\
\hline$>6215$ & $7(100.0)$ & $6(30.0)$ & $5(83.3)$ & $1(33.3)$ & \\
\hline $\begin{array}{l}\text { HIV RNA viral load } \\
\text { (CSF) * }\end{array}$ & & & & & 0.101 \\
\hline$\leq 177$ & $0(0.0)$ & $5(25.0)$ & $1(16.7)$ & $0(0.0)$ & \\
\hline > 177 & $3(42.9)$ & $3(15.0)$ & $1(16.7)$ & $0(0.0)$ & \\
\hline NA & $4(57.1)$ & $12(60.0)$ & $4(66.7)$ & $3(100.0)$ & \\
\hline $\begin{array}{l}\text { WBC count (blood) } \\
\left(\times 10^{9} \text { cells } / \mathrm{L}\right) *\end{array}$ & & & & & 0.994 \\
\hline$\leq 4.9$ & $4(57.1)$ & $10(50.0)$ & $3(50.0)$ & 1(33.3) & \\
\hline$>4.9$ & $3(42.9)$ & $9(45.0)$ & $3(50.0)$ & $1(33.3)$ & \\
\hline NA & $0(0.0)$ & $1(5.0)$ & $0(0.0)$ & $1(33.3)$ & \\
\hline $\begin{array}{l}\text { WBC count (CSF) } \\
\text { (cells/L)* }\end{array}$ & & & & & 0.494 \\
\hline$\leq 6$ & $3(42.9)$ & $12(60.0)$ & $1(16.7)$ & $1(33.3)$ & \\
\hline$>6$ & $4(57.1)$ & $7(35.0)$ & $3(50.0)$ & 1(33.3) & \\
\hline NA & $0(0.0)$ & $1(5.0)$ & $2(33.3)$ & 1(33.3) & \\
\hline
\end{tabular}




\begin{tabular}{|c|c|c|c|c|c|}
\hline \multirow[t]{2}{*}{ Feature } & $\begin{array}{l}\text { CMV } \\
\text { (FFPET) }\end{array}$ & $\begin{array}{l}\text { JCV } \\
\text { (FFPET) }\end{array}$ & $\begin{array}{l}\text { TG } \\
\text { (FFPET) }\end{array}$ & $\begin{array}{l}\text { No pathogen } \\
\text { (FFPET) }\end{array}$ & $\begin{array}{l}P \\
\text { value }\end{array}$ \\
\hline & No. (\%) & No. (\%) & No. (\%) & No. (\%) & \\
\hline TG IgG (CSF) & & & & & 0.013 \\
\hline Positive & $0(0.0)$ & $0(0.0)$ & $3(50.0)$ & $0(0.0)$ & \\
\hline Negative & $6(85.7)$ & $14(70.0)$ & $3(50.0)$ & $2(66.7)$ & \\
\hline NA & $1(14.3)$ & $6(30.0)$ & $0(0.0)$ & $1(33.3)$ & \\
\hline TG IgG (serum) & & & & & 0.005 \\
\hline Positive & $1(14.3)$ & $2(10.0)$ & $5(83.3)$ & $0(0.0)$ & \\
\hline Negative & $5(71.4)$ & $17(85.0)$ & $1(16.7)$ & $2(66.7)$ & \\
\hline NA & $1(14.3)$ & $1(5.0)$ & $0(0.0)$ & 1(33.3) & \\
\hline Number of lesions & & & & & 0.018 \\
\hline Solitary lesion & $1(14.3)$ & $3(15.0)$ & $1(16.7)$ & $3(100.0)$ & \\
\hline Multiple lesions & $6(85.7)$ & 17(85.0) & $5(83.3)$ & $0(0.0)$ & \\
\hline Symptomatic seizure & & & & & 0.285 \\
\hline Yes & $2(28.6)$ & $4(20.0)$ & $3(50.0)$ & $2(66.7)$ & \\
\hline No & $5(71.4)$ & $16(80.0)$ & $3(50.0)$ & 1(33.3) & \\
\hline
\end{tabular}

31 patients' data available for WBC (white blood cell) count in blood, range $1.24-15.21\left(\times 10^{9}\right.$ cells $/ \mathrm{L}$ ), the mean value was $4.9 \times 10^{9} \mathrm{cells} / \mathrm{L}$; WBC count in CSF (mean value 6, range 1-40) with 4 patients' data was unavailable. Yet, none of them was correlated with pathogen expression in FFPET $(P=0.994, P=0.494)$, so as the seizure incidence $(P=0.285)$.

Correlation analysis showed that IgG antibody against TG in $\operatorname{serum}(P=0.005)$ and in $\operatorname{CSF}(P=0.013)$ obviously correlated with TG expression in FFPET. All of the IgM against TG in CSF were negative, while there was only one positive for the IgM against TG in serum, whose FFPET PCR was TG positive.

In our study, the 0 pathogen patients tend to suffer from solitary lesion $(P=0.018)$. No patient was positive for anti-CMV IgM in serum, as well as the CMV PCR test in serum. Only one CSF PCR result was positive for CMV (the CMV-DNA load was 614, reference value is 0-500), whose FFPET PCR was positive for CMV and TG.

\section{Survival analysis}

In our study population, the total mortality rate was $42.42 \%$ (14/33). In univariate analysis (Fig. 2), compared with JCV negative patients, the JCV positive patients in FFPET had higher odds of death $(P=0.0096)$. Conversely, patients with TG positive showed lower odds of death $(P=0.0431)$, relative to other infections in FFPET. In addition, the TG positive patients were totally alive with improvement. There was no significant difference between CMV and other pathogen infected patients $(P>0.05)$.

\section{Discussion}


CNS Ols are the most common cause of neurological diseases in AIDS patients ${ }^{[2],[9]-[11]}$, the pathogens mainly include Cryptococcus neoformans, Mycobacterium tuberculosis, Toxoplasma gondii, CMV, JCV, EBV, VZV, HSV and various bacteria, fungi. Cryptococcus neoformans is the most common pathogen [4]-[6],[12],[13]. Pathogens often concurrent in AIDS patients, the symptoms and signs had no specificity, even the imaging features are also difficult to identify (Fig. 3). Thus, to comprehensively evaluate the microbiologic etiologies of CNS Ols in AIDS patients undoubtedly a great challenge in clinical work.

In terms of current routine test methods, including India ink stain, Cr Ag detection, Acid-fast stain, mycobacteria culture, immunoglobulin (lg) $\mathrm{G}$ and $\mathrm{M}$ antibody, pathological examination of cerebral parenchymal lesions, especially the development and wide application of CSF PCR in recent years, only the identification of Cryptococcus neoformans and

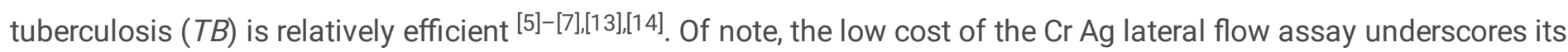
central role in the initial diagnosis of cryptococcal meningitis, that cannot be replaced by PCR test as the preferred assay for first episodes of cryptococcosis [15],[16]. Moreover, for TB diagnosis, the Xpert MTD/RIF assay is a fully automated nucleic acid amplification testing (NAAT) that can deliver a result in about $2 \mathrm{~h}$, Which was widely thought to be efficient and cost-effective ${ }^{[13]}$. It has been endorsed by the World Health Organization and widely deployed ${ }^{[17]-[22]}$.

Nevertheless, as yet, for most pathogens, especially the pathogens mainly caused cerebral parenchymal lesions, had low sensitivity and specificity means of diagnosis. In the clinical process, in most cases, the pathological examination of biopsy tissues can only exclude tumor or Mycobacterium tuberculosis, for most histopathological diagnosis only indicated inflammatory lesions, can't ascertain the pathogen, then simply given the empiric therapy. This not only increase the risk of blind medication, but also may delay the diagnosis and treatment of AIDS related CNS diseases.

In this study, we establish a set of FFPET PCR assay system, tried to identify the microbiologic etiologies for encephalitis, in a cohort of AIDS inpatients, who are without definite diagnosis. We selected CMV, TG and JCV for the targeted pathogens, which hyperendemic and frequently caused cerebral parenchyma lesions in AIDS patients, but difficult to ascertain by routine test methods ${ }^{[4]}$. The data suggested that the most common pathogen causing encephalitis is JCV. Our finding highlighted the utility and efficiency of the PCR assay for improving pathogen identification for CNS Ols.

JCV is the causative virus of progressive multifocal leukoencephalopathy (PML), which is a demyelinating disease of the CNS resulting from reactivation of JCV in immunocompromised patients ${ }^{[23]}$. JCV is a ubiquitous polyomavirus that infects $50 \%$ or more of the adult population throughout the world, the virus has also been found in the brains of otherwise normal individuals ${ }^{[24]}$.

Generally, the approach to diagnosis of PML was considered the demonstration of JCV DNA from CSF-PCR coupled with the appropriate clinical and imaging features ${ }^{[25]}$. Nevertheless, the sensitivity of CSF-JCV-PCR dropped from $89.5 \%$ in the pre- highly active antiretroviral therapy (HAART) era to $57.5 \%$ in the HAART era, and JCV positivity tends to occur in patients with lower $\mathrm{CD}_{4}$ cell counts ${ }^{[26]}$. Thus, the ability to detect JCV declines substantially following exposure to

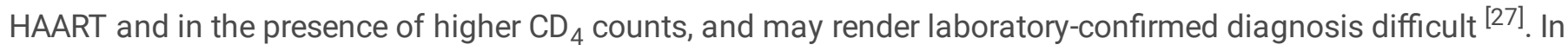
addition, since JC virus viremia can occur in healthy individuals, any contamination of the CSF with blood has the potential for providing a false-positive result [28],[29]. Moreover, some study showed that ${ }^{[30]}$, despite the high sensitivity of the PCR assay, a negative PCR does not rule out PML, in some cases biopsy of the brain with PCR amplification from the brain tissue has been employed to establish the diagnosis.

The neuropathologic definitive diagnosis of PML requires demonstration of the typical histopathologic triad (demyelination, bizarre astrocytes, and enlarged oligodendroglial nuclei) coupled with the techniques to show the 
presence of $\mathrm{JCV}{ }^{[31]}$. The histopathologic triad is rather convincing evidence of the disorder as this unique cluster is not observed in other neurologic disorders. Yet, there are examples in which PML has been misdiagnosed at the time of biopsy as a glioma ${ }^{[32]}$. Silver et al. ${ }^{[33]}$. reported that light microscopy and immunohistochemistry techniques alone may be insufficient in establishing the etiology and PCR enhances the yield when tissues obtained by stereotactic biopsy are nondiagnostic. Hence, either the clinical, imaging features or histopathological manifestations are unconvincing or CSF PCR is negative, the brain biopsy and cerebral parenchymal lesion PCR to assist in determining diagnostic certainty in these circumstances is provided.

$\mathrm{CMV}$ is also a ubiquitous agent that can cause infection during the course of life at any time ${ }^{[34],[35]}$. By serology, 30$100 \%$ of the general population exhibit prior exposure to the virus ${ }^{[36]}$. CMV remains latent in the infected host throughout life and rarely reactivates to cause clinical illness except in immunocompromised individuals [37]-[41].

In AIDS patients, CMV is a major cause of morbidity and mortality ${ }^{[41]}$. Transmission through sexual appears to be the most common route of CMV infection in adults [42],[43]. The CMV neurological disease usually occurs at ${ }^{C D_{4}}$ cell counts $<100$ cells/ul [7],[37], which approximately coincided with our study (median value 33, range 6-189).

The routine diagnostic methods for CMV in CNS were serology, CSF-PCR and histopathology respectively. Serological test is mainly the detection of anti-CMV IgG and IgM antibody. A study reports that $93.9 \%$ of the AIDS patients were positive for anti-CMV IgG antibody, and $11.1 \%$ were anti-CMV IgM antibody positive ${ }^{[41]}$. Nevertheless, for most of these patients, the diseases caused by CMV is so mild or asymptomatic that it is overlooked, which bring about the fact that AIDS patients are commonly positive for CMV by serology, but the CMV merely being a bystander [5][41].

Rongrong Yang et al. ${ }^{[4]}$ detected the CMV by CSF-PCR. Among the CMV-DNA positive patients, selected 6 patients who had the brain CT or MRI examination, no patient was found with brain parenchymal lesion. That reflected this method having a high false positivity to a certain extent.

Other research reported that diagnosis of CMV infection from tissue biopsies is considered the gold standard with specificity for histopathological evaluation near $100 \%$ but with low sensitivity $(23.2 \%)^{[44]}$.

Toxoplasma encephalitis (TE) is a very relevant neurological disease in individuals with AIDS ${ }^{[45]}$. This disease is caused by the intracellular protozoan parasite, TG. Immunocompetent persons with primary TG infection are usually asymptomatic, and latent infection can persist for the life of the host. In immunosuppressed patients, especially patients with AIDS, TG can reactivate and cause disease, usually when the $\mathrm{CD}_{4}$ count falls below 100 cells/ul, which also coincided with our study approximately (median value 75.5 , range 12-130).

Laboratory testing is usually necessary to establish the diagnosis of TE, because the clinical manifestations of infection are so protean. Available diagnostic modalities for TG include serologic assays, molecular-based techniques (eg, PCR based assays), and histopathology.

The serologic assays mainly conclude the IgG and IgM antibody. However, false-negative serologic testing is typically seen in patients among those who are significantly immunocompromised (eg, transplant patients, especially bone marrow transplants, or those with HIV infection) [46],[47]. And a false-positive IgM test result may be related to rheumatoid factor, antinuclear antibodies, and nonspecific binding in vitro, that's also a significant issue in serologic testing for toxoplasmosis ${ }^{[48]}$. Likewise, although detection of $\operatorname{lgG}$ and $\operatorname{lgM}$ antibody in CSF was also widely used, the CSF antibody tests can be confounded by contamination of the CSF by serum during the lumbar puncture, or passive transfer of antibody from the blood. 
The PCR assays can detect TG DNA in blood, cerebrospinal fluid, aqueous humor, and bronchoalveolar lavage fluid [49], [50]. Since there is no standardized PCR assay, the sensitivity of PCR assays varies widely (from 15 to 85 percent for blood), although specificity appears to be high (greater than 95 percent) ${ }^{[51]}$. Depending upon another studies, the detection of TG by PCR in CSF has demonstrated high specificity (96 to 100 percent), but variable sensitivity (50 to 98 percent). Treatment also affects diagnostic sensitivity [52],[53]. Thus, a positive PCR result establishes the diagnosis of $\mathrm{TE}$, but a negative one does not rule it out.

Histopathological detection of TG is in one of two forms: tachyzoites or cysts ${ }^{[47]}$. Nevertheless, they were all rarely or difficult detected in the cerebral parenchymal lesion tissue ${ }^{[54]}$.

The ultimate significance of PCR based detection of toxoplasmosis is that PCR can detect the DNA of parasites even when the tissues available for testing are in state of decomposition; in contrast, in histopathology it is quite difficult to identify the necrosed tachyzoites in the regions of marked generalized necrosis of the parent tissues induced by tachyzoites themselves ${ }^{[54]}$. Moreover, the size of the sample analyzed is very important in the detection by histopathology and it is quite possible that the parasitic stage in the sample to be tested is either low or sparse and show focal distribution in the tissues or it may be all together dead. But PCR will give amplification even if the parasitic stage is dead ${ }^{[55]}$ and/or very less in number. PCR can even detect $0.1 \mathrm{pg}$. of DNA ${ }^{[56]}$ and even a very few tachyzoites are sufficient in accurate diagnosis no matter if they are living or dead.

Our study showed there was no patient's WBC counts higher than $20 \times 10^{9} \mathrm{cells} / \mathrm{L}$ in blood. Likewise, the WBC count in CSF did not exceed 40 cells/L in our study. This reflected from the side that blood and CSF were not so sensitive to the encephalitis, in other words, they cannot accurately reflect the severity of encephalitis.

In our study population, the total mortality rate was $42.42 \%(14 / 33)$, that mainly focus on the JCV and CMV patients. The patients with FFPET TG positivity were totally alive with improvement, that because all of the patients in our study were routinely received the empirical/experimental anti-toxoplasma therapy after the operation when the histopathological diagnosis only indicated inflammatory lesions. This is not only because the TE is prevalent in AIDS patients, but also the other pathogens, like CMV and JCV, have no specific, effective treatment. For this reason, the application of PCR assay for the cerebral parenchymal lesions, not only improving pathogen identification efficiency, but also lay a foundation for further research of pathological mechanism and precise treatment of CNS Ols.

In our study, the variety of specific pathogens for PCR testing was limited and there are other possible pathogens of CNS infection, but were not assessed. For instance, we excluded the Epstein-Barr virus (EBV) and herpes simplex viruses $(H S V)$, the reasons are as follows:

EBV was not validated by additional confirmatory testing due to its ubiquitous nature and unclear significance in this immunocompromised population, as described previously ${ }^{[5],[6]}$. In line with a study by Kelly et al. ${ }^{[7]}$ speculated that EBV might be a non-pathogenic marker of immunosuppressed population. Furthermore, another research showed that EBV was left out of an FDA-approved PCR panel, and the prevalence of EBV should be interpreted with caution, especially lacking confirmatory PCR testing ${ }^{[5]}$. Rajasingham et al. ${ }^{[57]}$ thought that there is little need for expansion of HSV PCR testing. Although if further patients were tested, HSV likely would have been detected, the prevalence appears quite low and testing would not be cost-effective compared with other interventions.

On account of our study is a retrospective analysis, these patients lacked the pertinent therapy at that time, so we cannot further appraise the accuracy of this method effectively. Consequently, additional studies to validate the accuracy of PCR assay in the diagnosis of cerebral parenchymal Ols are needed across the further prospective study. Our study is 
also limited by the relatively small sample size, so multiple pathogens infection in CNS disorder patients will be an important topic to assess with further study in larger cohorts and with subsequent validation of results.

In terms of economic effectiveness, it seems that the introduction of the PCR assay would result in more rapid and accurate diagnosis along with minimization of unnecessary testing, a shortened time to initiation of targeted therapy, and shorter hospital durations, which have a substantial cost savings in countries ${ }^{\left[{ }^{[5]}[58]\right.}$. Whereas, to validate the costeffectiveness of the PCR assay method in the diagnosis and monitoring of cerebral parenchymal infections are also needed further studies.

In summary, the PCR assay offers a promising platform for the rapid and accurate diagnosis of cerebral parenchymal infections, but need further efforts to validate.

\section{Abbreviations}

CNS: Central nervous system; Ols: opportunistic infections; AIDS: Acquired Immune Deficiency Syndrome; PCR: polymerase chain reaction; FFPET: formalin-fixed paraffin-embedded tissue; CMV: cytomegalovirus; JCV: John Cunningham virus; TG: toxoplasma gondii; WBC: white blood cell; CSF: cerebrospinal fluid; Cr Ag: Cryptococcal antigen; PML: progressive multifocal leukoencephalopathy; HAART: highly active antiretroviral therapy; EBV: Epstein-Barr virus; HSV: herpes simplex viruses.

\section{Declarations}

\section{Authors' contributions}

Bo Liang: study designing and manuscript writing;

Siyuan Yang: experiment designing and data analysis;

Tingyu Liang: data collection and analysis;

Hongxin Zhao: study designing and specimen collection;

Xinghuan Ding: specimen collection and data analysis;

Fang Wang: specimen and data collection;

Enshan Feng: study designing.

\section{Acknowledgments}

We thank the Beijing Medical Management Center Cultivation plan in the writing of the manuscript and experiment designing.

We thank the National Natural Science Foundation of China in designing the study. We thank the Thirteen-Fifth Key Project for specimen collection.

We thank the Beijing Hospital Authority “Dengfeng” Talent Training Plan for data analysis.

\section{Competing interests}




\section{Availability of data and materials}

The datasets supporting the conclusions of this article are included within the article.

\section{Ethical Approval and consent to participate}

The study was approved by Beijing Ditan hospital of Capital Medical University Ethics Committee.

Written consent forms were obtained from the patients after gave them appropriate information.

\section{Funding}

This work is supported by grant from the Beijing Medical Management Center Cultivation plan (PX2020071) and the National Natural Science Foundation of China (81672000) and the Thirteen-Fifth Key Project (2018ZX10715-005) and the Beijing Hospital Authority “Dengfeng” Talent Training Plan (DFL20191802).

\section{References}

1. Riveiro-Bardela M, Falco V, Burgos J, et a1. Neurological opportunistic infections and neurological immune reconstitution syndrome: impact of one decade of highly active antiretroviral treatment in a tertiary hospital [J]. HIV Medicine, 2013, 14(1): 21-30.

2. Weisberg LA. Neurologic abnormalities in human immunodeficiency virus infection [J]. South Medicine Journal. 2001, 94(3): 266-275.

3. Hill JA, Mayer BT, Xie H, et al. The cumulative burden of double-stranded DNA virus detection after allogeneic HCT is associated with increased mortality [J]. Blood, 2017, 29(10): 2316-2325.

4. Rong rong Yang, Hong Zhang, Yong Xiong, et al. Molecular diagnosis of central nervous system opportunistic infections and mortality in HIV-infected adults in Central China [J]. AIDS Research and Therapy, 2017, 14(24): 31-37.

5. Joshua Rhein, Nathan C Bahr, Andrew C, et al. Diagnostic Performance of a Multiplex PCR assay for meningitis in an HIV-infected population in Uganda [J]. Diagnostic Microbiology and Infectious Disease, 2016, 84(3): $268-273$.

6. Radha Rajasingham, Joshua Rhein, Kate Klammer, et al. Epidemiology of Meningitis in an HIV-Infected Ugandan Cohort [J]. American Journal of Tropical Medicine and Hygiene, 2015, 92(2): 274-279.

7. Matthew J. Kelly, Laura A. Benjamin, Katharine Cartwright, et al. Epstein-Barr virus coinfection in cerebrospinal fluid is associated with increased mortality in Malawian adults with bacterial meningitis [J]. The Journal of Infectious Diseases, 2012, 205: 106-110.

8. Du-Bois Asante, Richard Harry Asmah, Andrew Anthony Adjei, et al. Detection of Human Papillomavirus Genotypes and Epstein-Barr Virus in Nasopharyngeal Carcinomas at the Korle-Bu Teaching Hospital, Ghana [J]. The Scientific World Journal, 2017,3(9):1-9.

9. Isezuo SA, Sani AZ, Ezunu E, et al. Clinical neuropathy in HIV/AIDS: an eight-year review of hospitalized patients in Sokoto, northwestern Nigeria [J]. Tropical Doctor, 2009, 39(3): 133-135.

10. Modi M, Mochan A, Modi G. Management of HIV-associated focal brain lesions in developing countries [J]. QJM, 2004, 97(7): 413-421. 
11. World Health Organization. WHO case definitions of HIV for surveillance and revised clinical staging and immunological classification of HIV related disease in adults and children [J]. Geneva: World Health Organization, 2007,10-38.

12. Garvey L, Winston A, Walsh J, et al. HIV囚associated central nervous system diseases in the recent combination antiretroviral therapy era [J]. European Journal of Neurology, 2011, 18: 527-534.

13. Cohen DB, Zijlstra EE, Mukaka M, et al. Diagnosis of cryptococcal and tuberculous meningitis in a resource limited African setting [J]. Tropical Medicine \& International Health, 2010,15(8): 910-917.

14. Cowan JF, Chandler AS, Kracen E, et al. Clinical impact and cost-effectiveness of Xpert MTB/RIF testing in hospitalized patients with presumptive pulmonary tuberculosis in the United States [J]. Clinical Infectious Diseases, 2017, 64(4): 482-9.

15. Boulware DR, Meya DB, Bergemann TL, et al. Clinical features and serum biomarkers in HIV immune reconstitution inflammatory syndrome after cryptococcal meningitis: A prospective cohort study [J]. PLoS Medicine, 2010, 7: 1000384.

16. Durski KN, Kuntz KM, Yasukawa K, et al. Cost-effective diagnostic checklists for meningitis in resource-limited settings [J]. Journal of Acquired Immune Deficiency Syndromes, 2013, 63: 101-108.

17. Denkinger CM, Schumacher SG, Boehme CC, et al. Xpert MTB/RIF assay for the diagnosis of extrapulmonary tuberculosis: a systematic review and meta-analysis [J]. European Respiratory Journal, 2014, 44(2): 435-446.

18. Steingart KR, Schiller I, Horne DJ, et al. Xpert MTB/RIF assay for pulmonary tuberculosis and rifampicin resistance in adults [J]. Cochrane Database Systematic Reviews, 2014, 4: CD009593.

19. Langley I, Lin HH, Squire SB. Cost-effectiveness of Xpert MTB/RIF and investing in health care in African [J]. Lancet Global Health, 2015, 3: 83-84.

20. Lawn SD, Mwaba P, Bates M, et al. Advances in tuberculosis diagnostics: the Xpert MTB/RIF assay and future prospects for a point-of-care test [J]. Lancet Infectious Disease, 2013, 13: 349-361.

21. Creswell J, Codlin AJ, Andre E, et al. Results from early programmatic implementation of Xpert MTB/RIF testing in nine countries [J]. BMC Infectious Disease, 2014, 14: 2.

22. Cowan JF, Michel C, Manhica I, et al. Implementing rapid testing for tuberculosis in Mozambique [J]. Bull World Health Organ, 2015, 93: 125-130.

23. A.J. Martínez, M. Sell, T. Mitrovics, et al. The neuropathology and epidemiology of AIDS. A Berlin experience. A review of 200 cases [J]. Pathology Research and Practice, 1995, 191: 427-443.

24. White MK, Khalili K. Pathogenesis of progressive multifocal leukoencephalopathy: revisited [J]. Journal of Infectious Disease, 2011, 203: 578-586.

25. Cinque P, Koralnik IJ, Clifford DB. The evolving face of human immunodeficiency virus-related progressive multifocal leukoencephalopathy: defining a consensus terminology [J]. Journal of Neurovirol, 2003, 9: 88-92.

26. Wang Y, Kirby JE, Qian Q, et al. Effective use of JC virus PCR for diagnosis of progressive multifocal leukoencephalopathy [J]. Journal of Medical Microbiol, 2009, 58: 253-255.

27. Marzocchetti A, Di Giambenedetto S, Cingolani A, Ammassari A, Cauda R, De Luca A. Reduced rate of diagnostic positive detection of JC virus DNA in cerebrospinal fluid in cases of suspected progressive multifocal leukoencephalopathy in the era of potent antiretroviral therapy [J]. Journal of Clinical Microbiol, 2005, 43: 41754177.

28. lacobaeus E, Ryschkewitsch C, Gravell M, et al. Analysis of cerebrospinal fluid and cerebrospinal fluid cells from patients with multiple sclerosis for detection of JC virus DNA [J]. Multiple Sclerosis Journal, 2009, 15: 28-35.

29. Berger, J. R., Aksamit, A. J., Clifford, D. B, et al. PML diagnostic criteria: consensus statement from the AAN Neuroinfectious Disease Section [J]. Neurology, 2013, 80(15): 1430-1438. 
30. Kuhle J, Gosert R, Buhler R, et al. Management and outcome of CSF-JC virus PCR-negative PML in a natalizumabtreated MS patient [J]. Neurology, 2011, 77: 2010-2016.

31. Astrom KE, Mancall EL, Richardson EP Jr. Progressive multifocal leuko-encephalopathy; a hitherto unrecognized complication of chronic lymphatic leukaemia and Hodgkin's disease [J]. Brain, 1958, 81: 93-111.

32. Van Assche G, Van Ranst M, Sciot R, et al. Progressive multifocal leukoencephalopathy after natalizumab therapy for Crohn's disease [J]. The New England Journal of Medicine, 2005, 353: 362-368.

33. Silver SA, Arthur RR, Erozan YS, Sherman ME, McArthur JC, Uematsu S. Diagnosis of progressive multifocal leukoencephalopathy by stereotactic brain biopsy utilizing immunohistochemistry and the polymerase chain reaction [J]. Acta Cytologica, 1995,39: 35-44.

34. Akinbami AA, Akanmu AS, Adeyemo TA, Wright KO, Dada MO, Dosunmu AO. Cytomegalovirus antibodies among healthy blood donors at Lagos University Teaching Hospital [J]. South African Medical Journal, 2009, 99 (7): 528 530

35. Spector SA, Wong R, Hsia K, et al. Plasma cytomegalovirus (CMV) DNA load predicts CMV disease and survival in AIDS patients [J]. Journal of Clinical Investigation, 1998, 101:497-502.

36. de Matos SB, Meyer, R, de Mendonça Lima, FW. Seroprevalence and serum profile of cytomegalovirus infection among patients with hematologic disorders in Bahia State, Brazil [J]. Journal of Medical Virology, 2010, 83 (2): 298 304.

37. Wohl DA, Zeng D, Stewart P, et al. Cytomegalovirus viremia, mortality, and end-organ disease among patients with AIDS receiving potent antiretroviral therapies [J]. Journal of Acquired Immunodeficiency Syndrome, 2005, 38: 538544.

38. Krech U. Complement-fixing antibodies against cytomegalovirus in different parts of the world [J]. Bulletin of World Health Organization, 1973, 49(1): 103-106.

39. Grefte A, van der Giessen M, van Son W, The TH. Circulating cytomegalovirus (CMV)-infected endothelial cells in patients with an active CMV infection [J]. Journal of Infectious Diseases, 1993, 167 (2): 270-277.

40. Akinbami AA, Akanmu AS, Adeyemo TA, Wright KO, Dada MO, Dosunmu AO. Cytomegalovirus antibodies amongst immunocompromised (HIV) patients at Lagos University Teaching Hospital (LUTH) Idi-Araba, Lagos [J]. Journal of Medicine, 2010, 11: 151-154.

41. Adeola Fowotade, Iheanyi Omezuruike Okonko, Olajide Olubunmi Agbede. High seropositivity of IgG and IgM antibodies against cytomegalovirus (CMV) among HIV-1 seropositive patients in Ilorin, Nigeria [J]. African Health Sciences, 2015,15(1): 1-9.

42. Dollard S, Grosse S, Ross D. New estimates of the prevalence of neurological and sensory sequelae and mortality associated with congenital cytomegalovirus infection [J]. Review of Medical Virology, 2007; 17(5):355-363.

43. Akinbami AA, Akanmu AS, Adeyemo TA, Wright KO, Dada MO, Dosunmu AO. Cytomegalovirus Antibodies Amongst Immunocompromised (HIV) Patients At Lagos University Teaching Hospital (LUTH) Idi-Araba, Lagos [J]. Journal of Medicine, 2010, 11: 151-154.

44. Kotler DP, Reka S, Borcich A, Cronin WJ. Detection, localization, and quantitation of HIV-associated antigens in intestinal biopsies from patients with HIV [J]. American Journal of Pathology, 1991,139: 823-30.

45. Manzardo C, Del Mar Ortega M, Sued O, Garcia F, Moreno A, Miro JM. Central nervous system opportunistic infections in developed countries in the highly active antiretroviral therapy era [J]. Journal of Neuroviral, 2005, 11(suppl 3): 72-82.

46. Montoya JG. Laboratory diagnosis of Toxoplasma gondii infection and toxoplasmosis [J]. Journal of Infectious Disease, 2002, 185: S73.

47. Montoya JG, Liesenfeld O. Toxoplasmosis [J]. Lancet, 2004, 363: 1965.

Page $14 / 16$ 
48. Liesenfeld O, Press C, Montoya JG, et al. False-positive results in immunoglobulin M ( $\lg M)$ toxoplasma antibody tests and importance of confirmatory testing: the Platelia Toxo IgM test [J]. Journal of Clinical Microbiology, 1997, 35: 174.

49. Dupouy-Carnet J, de Souza SL, Maslo C, et al. Detection of Toxoplasma gondii in venous blood from AIDS patients by polymerase chain reaction [J]. Journal of Clinical Microbiology, 1993, 31: 1866.

50. Mele A, Paterson PJ, Prentice HG, et al. Toxoplasmosis in bone marrow transplantation: a report of two cases and systematic review of the literature [J]. Bone Marrow Transplant, 2002, 29: 691.

51. Bastien P. Molecular diagnosis of toxoplasmosis [J]. Transactions of the Royal Society of Tropical Medicine \& Hygiene, 2002, 96: S205.

52. Nogui FL, Mattas S, Turcato Junior G, Lewi OS. Neurotoxoplasmosis diagnosis for HIV-1 patients by real-time PCR of cerebrospinal fluid [J]. Brazilian Journal of Infectious Diseases, 2009, 13: 18.

53. Mesquita RT, Ziegler AP, Hiramoto RM, et al. Real-time quantitative PCR in cerebral toxoplasmosis diagnosis of Brazilian human immunodeficiency virus-infected patients [J]. Journal of Medical Microbial, 2010, 59: 641.

54. Vikrant Sudan, A.K. Tewari, R. Singh, Harkirat Singh. Comparison of histopathology and PCR based assay for detection of experimentally induced toxoplasmosis in murine model [J]. Asian Pacific Journal of Tropical Medicine, 2015,8(6): 447-450.

55. Wastling JM, Nicoll S, Buxton D. Comparison of two gene amplification methods for the detection of Toxoplasma gondii in experimentally infected sheep [J]. Journal of Medical Microbiology, 1993, 38: 360-365.

56. MacPherson JM, Gajadhar AA. Sensitive and specific polymerase chain reaction detection of Toxoplasma gondii for veterinary and medical diagnosis [J]. American Journal of Veterinary Research, 1993, 57: 45-48.

57. Rajasingham R, Rolfes MA, Birkenkamp KE, Meya DB,Boulware DR. Cryptococcal meningitis treatment strategies in resource-limited settings: a cost-effectiveness analysis [J]. PLoS Medicine, 2012, 9: 1001316.

58. Rhein J, Boulware DR. Prognosis and management of cryptococcal meningitis in patients with human immunodeficiency virus infection [J]. Neurobehavioral HIV Medicine, 2012, 4:45.

\section{Figures}

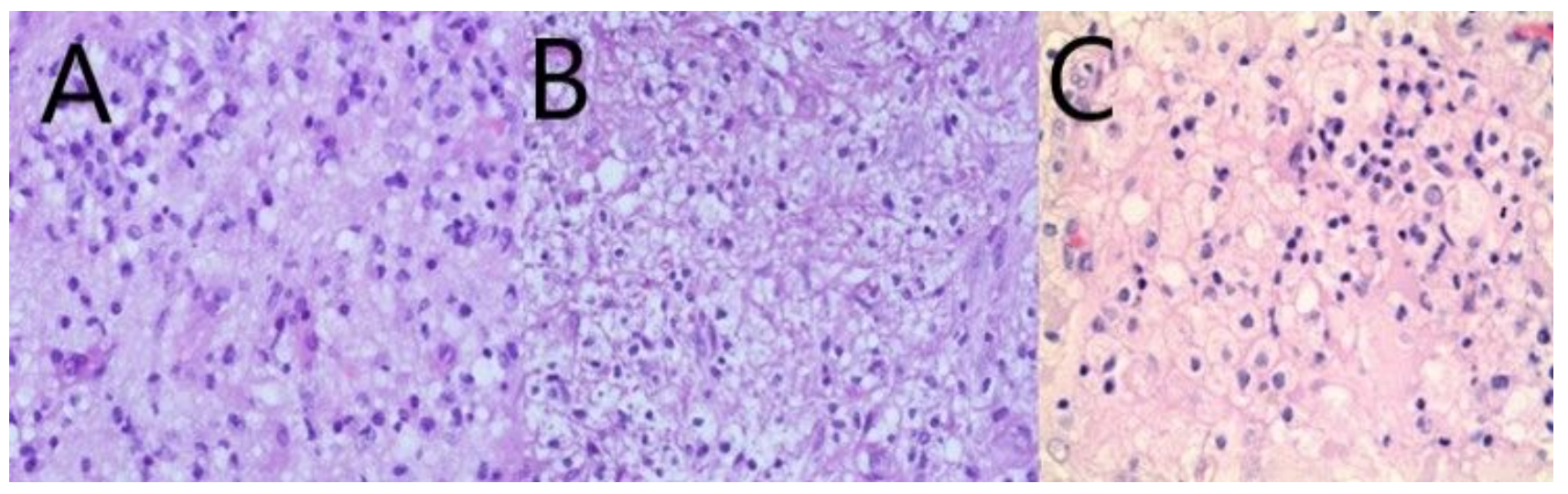

\section{Figure 1}

Photomicrograph of the histopathological inflammatory lesions. A, B, C: Histopathological diagnosis only indicated inflammatory, infective, demyelinating lesions: which presented that glial cells and microvasculature hyperplasia, infiltration with monocyte, macrophage, microglia, plasmacyte, lymphocyte, intracytoplasm or intranuclear inclusion body formation (H\&E stain 400x). The FFPET PCR results from A to C were TG, JCV, CMV. 

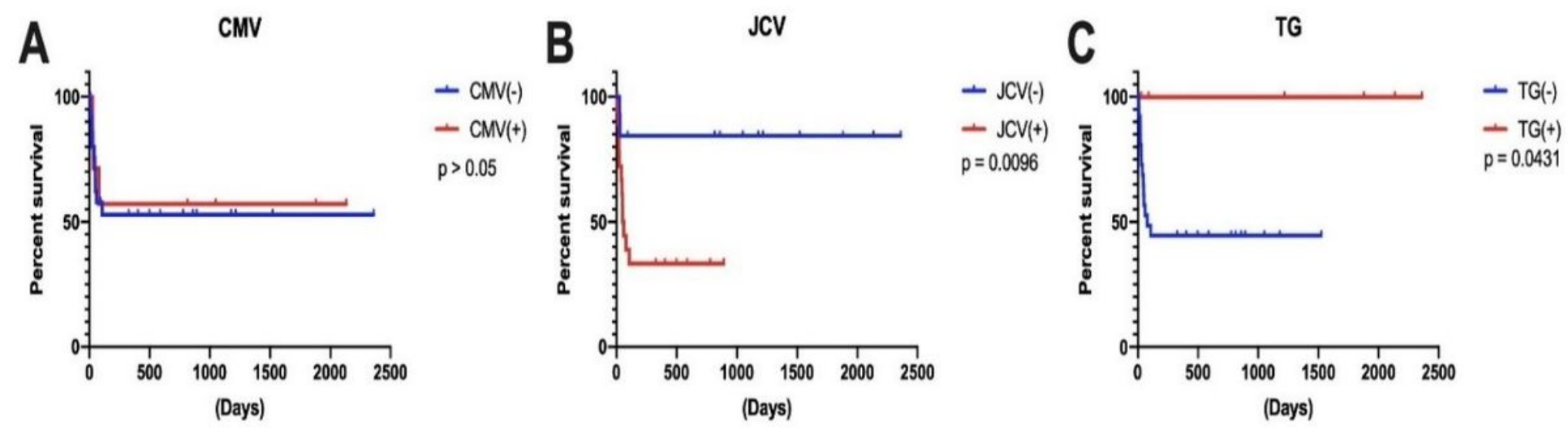

Figure 2

Univariate analysis for survival of cerebral parenchyma infected by different pathogens in AIDS patients. A: CMV infection for AIDS patients' cerebral parenchyma; B: JCV infection for AIDS patients' cerebral parenchyma; C: TG infection for AIDS patients' cerebral parenchyma.

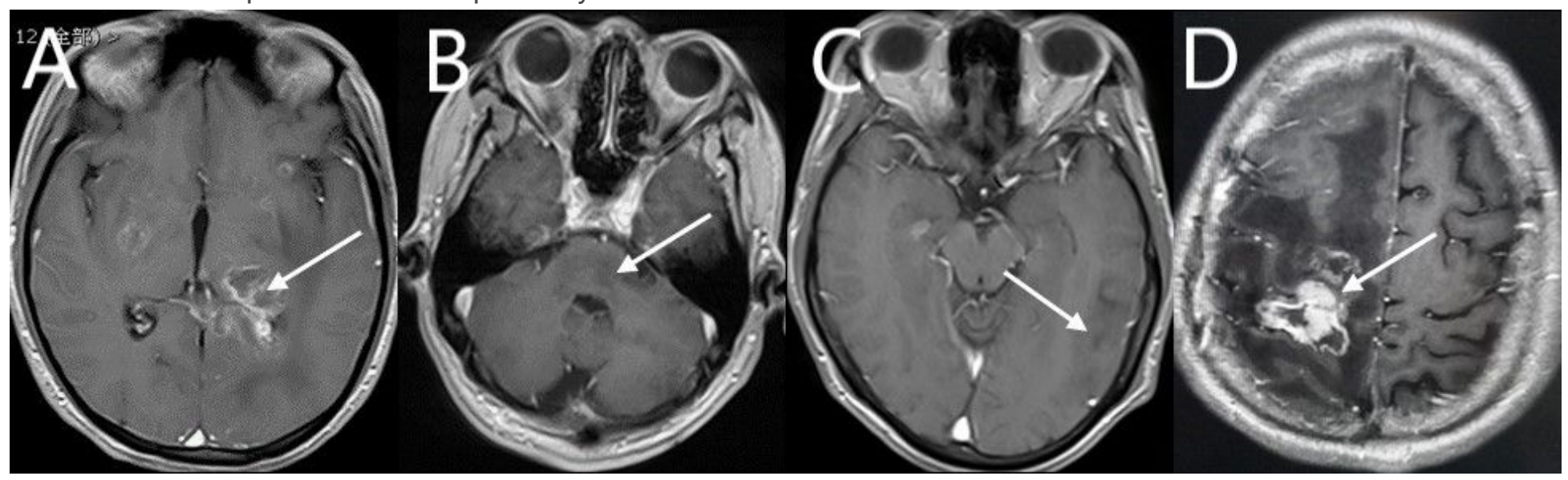

Figure 3

AIDS related cerebral parenchyma lesions by Enhanced-MRI examination. A, B, C: The histopathological diagnosis merely showed inflammatory lesions, the results of FFPET PCR were TG, JCV, CMV respectively; D: histopathological diagnosed with lymphoma. It's so difficult to identify from each other by imaging features. 